
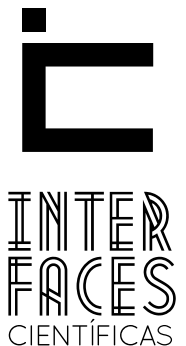

EDUCAÇÃO

\title{
METODOLOGIA DA PESQUISA: RECORDE SOBRE MÍDIA NA EDUCAÇÃO
}

Maria Neide Sobral ${ }^{1}$

\section{RESUMO}

Nesse estudo, procuramos apresentar algumas abordagens sobre pesquisa em educação, fazendo alguns recortes sobre mídia nos processos de ensinar e aprender por considerarmos um tema que tem despertado cada vez mais o interesse dos investigadores nesse campo de conhecimento na atualidade. Neste sentido, procuramos elencar alguns elementos discursivos sobre a metodologia da pesquisa, do ponto de vista didático, refletindo sobre questões delineadoras da investigação no campo da educação, a saber: enfoques teóricos e abordagens metodológicas, tomando como referências possíveis objetos de pesquisa sobre mídia na educação.

\section{PALAVRAS-CHAVE}

Metodologia da Pesquisa. Abordagem. Enfoque. Mídias na Educação

\section{ABSTRACT}

In this study, we discuss some approaches to research education, doing some media clippings about the processes of teaching and learning, since this theme has aroused increasing interest of researchers in this field of knowledge. In this sense, we try to list some discursive elements about research methodology, the teaching point of view, reflecting on issues of research in the field of education, as, for example, theoretical issues and methodological approaches, taking potential research subjects on media education as reference.

\section{KEYWORDS}

Research Methodology. Approach. Media in Education 


\section{RESUMEN}

En este estudio, se discuten algunos enfoques de la investigación en educación, haciendo algunos recortes de prensa acerca de los procesos de enseñanza y aprendizaje, porque consideramos que es un tema que ha despertado el creciente interés de los investigadores en este campo del conocimiento en la actualidad. En este sentido, tratamos de incluir algunos elementos del discurso sobre la metodología de la investigación, el punto de vista didáctico, reflexionando sobre los temas de investigación delineadoras en el campo de la educación, a saber: enfoques teóricos y metodológicos, tomando como referencia objetos posibles de la investigación sobre medios de comunicación en la educación.

\section{PALABRAS CLAVE}

Metodología de la Investigación. El Enfoque. La Educación en Medios.

\section{INTRODUÇÃO}

Ao nos debruçarmos sobre o tema "pesquisa em educação", estamos tratando, necessariamente, de uma discussão sobre objetos de estudo de natureza interdisciplinar, pensando na educação como uma prática social e cultural que se alicerça de diferentes saberes para se efetivar: científicos, estéticos, artísticos, religiosos, dentre outros. Educação, em sentido amplo, "é uma ação exercida por meio de métodos particulares, com o objetivo de desenvolvimento ou preparação social, intelectual, moral, física e afetiva da criança ou jovem" (QUEIROZ, 2003). Essa prática permite a transmissão (interpretação) de elementos culturais entre gerações. Assim, quando estamos tratando do campo educacional, estamos mapeando frentes de estudos diferenciados, múltiplos e em aberto, que contribuem para o entendimento e aplicação dos conhecimentos científicos no referido campo.

Entendemos o conhecimento científico como resultante da ação humana, "otimizando o uso da sua racionalidade, realiza-se de forma sistemática, metódica e crítica da sua função de desvelaro mundo, compreendê-lo, explicá-lo e dominá-lo" (KÖCHE, 1997, p. 29). 0 saber científico é, portanto, produto da realização de estudos realizados de forma sistemática, com utilização de um método de pesquisa, fundamentados teoricamente e alicerçados em dados empíricos, de modo a conduzir a determinados achados, conclusões ou entendimentos reflexivos sobre problemas no campo educacional. Assim, a produção do conhecimento científico, na educação, passa pelos mesmos crivos que qualquer outra área de saber na busca de princípios explicativos da realidade educacional.

A necessidade de critérios de cientificidade tem conduzido muitos pesquisadores a buscarem conceitos e métodos de ciências já constituídas, fazendo sua aplicação ao campo da educação educacional. Compreendemos a natureza interdisciplinar dos objetos nesse campo do conhecimento e a necessidade de buscar o diálogo entre as ciências para tentar problematizar e encaminhar soluções para a questão da pesquisa educacional. Podemos considerar que os fenômenos educacionais estão situados no âmbito das ciências humanas ou sociais ${ }^{1}$, que têm lhes servido de modelos investigativos. A educação é um campo investiga-

1 Não há consenso em relação à classificação das ciências entre os autores. Marconi e Lakatos (2008) dividem as ciências formais (lógico-matemática) factuais (naturais e humanas); Chauí (2006) em ciências matemáticas, ciências naturais, ciências humanas ou sociais e ciências aplicadas. 
tivo multifacetado e aberto, cabendo, por isso, inúmeros objetos de estudo, sempre em situação fronteiriça entre as ciências. Objetos que podem ganhar o status de mestiço, no sentido de Gruzinski (2004), dadas as suas características interculturais e internacionais por ultrapassarem fronteiras de países, continentes e permitir sempre um diálogo entre quem educa e quem é educado, independente de qualquer cultura.

Assim, como as ciências humanas ou sociais seguiram, por muito tempo, o modelo das ciências físicas e naturais na busca da construção do conhecimento científico, o objeto em educação também se serviu desse modelo como afirma Lücke e André (1985, p. 3):

0 fenômeno educacional foi estudado por muito tempo como se pudesse ser isolado, como se faz com uns fenômenos físicos, para uma análise, acurada, se possível feita em um laboratório, onde as variáveis que o compõem pudessem também ser isoladas, a fim de se constatar a influência que cada uma delas exerceria sobre o fenômeno em questão.

Cada objeto de estudo no campo da educação trás, de forma explicita ou implícita, enfoques teóricos que norteiam a metodologia e a análise dos dados. No geral, esse quadro referencial advém das ciências humanas ou sociais. 0 referencial teórico tem o papel pedagógico de nos aproximação com nosso objeto de pesquisa, não como “uma malha pré-fabricada”, mas como "um esquema geométrico, uma espécie de organograma, um encaixe, onde forçaríamos os dados para que eles se adequassem bem" (SEVERINO, 2004, p. 32).

Nesse estudo, procuramos abordar pressupostos teóricos e metodológicos sobre a pesquisa em educação, fazendo alguns recortes sobre mídia nos processos de ensinar e aprender, por considerarmos, na atualidade, um tema que tem despertado cada vez mais o interesse dos investigadores nesse campo de conhecimento. A despeito do número significativo de publicações sobre estudos realizados na área ${ }^{2}$, esses não traduzem claramente as implicações teóricas e metodológicas do campo da pesquisa em ciências humanas ou sociais. Com esse objetivo, procuramos delinear algumas reflexões sobre enfoques, abordagens e tipos de pesquisa no campo da educação, sinalizando para objetos sobre a produção do conhecimento sobre o tema "Mídia e Educação". Mídia entendida aqui como suporte tecnológico e meio comunicacional que possibilita, no processo educacional, formas interações entre professores e alunos capazes de apoiar, motivar, estruturar formas e processos de aprendizagem. A integração de diferentes mídias em suportes digitais é chamada de Tecnologias da Informação e Comunicação (TIC).

\section{ENFOQUES TEÓRICOS: UM APANHADO}

Consideramos que a educação alicerça-se, sobretudo, dos quadros referenciais das ciências humanas ou sociais para se fazer enquanto prática investigativa. Por isso, submersa no movimento de saltos e rupturas dessas ciências, a despeito de ter criado um campo singular, com determinadas particularidades.

Assim, a prática investigativa em educação esteve no bojo das emergentes humanas ou sociais, constru- ída dentro do chamado paradigma dominante, no qual as ciências naturais se estabeleceram. Paradigma entendido no sentido de Kuhn (1997), como uma constelação de ideias, métodos, tecnologias, procedimentos partilhados por uma determinada comunidade cientí-

\footnotetext{
2 Mercado tem organizado várias obras que trazem como tema central práticas, pesquisas e estudos sobre as Tecnologias da Informação e Comunicação nas modalidades de ensino presencial e a distância (MERCADO: 2002; 2005; 2008)
} 
fica na prática da ciência normal, isto é, no interior de um paradigma estabelecido. Quando emerge alguma anomalia nessa prática ou surgem novos elementos que não são explicáveis dentro do referido paradigma, cria-se outro, não só abandonando a forma de fazer da ciência antiga, rompendo com ela e dando saltos ou revoluções (CHAUÍ, 2000).

Santos (2003) chama de paradigma dominante o modelo de racionalidade que tem prevalecido na ciência moderna desde o século XVI, quando o conhecimento científico se apartou da filosofia ou como afirma o autor, do saber medieval aristotélico, separando o conhecimento científico do conhecimento comum, entre natureza e pessoa humana. Prevaleceu a observação e a experimentação como eixos fundantes de um conhecimento rigoroso e a matemática como lógica da investigação. Conhecer significa quantificar, o que não é mensurável é irrelevante. Por isso, se torna necessário simplificar o fenômeno estudado em partes, classificá-los e estabelecer relações sistemáticas entre elas. A metáfora de mundo-máquina de Newton é bem apreendida aqui. É preciso conhecer as partes dessa máquina, sua mecânica, como possibilidade concreta de se chegar à verdade. No seio desse paradigma dominante, as ciências humanas ou sociais emergem, já no século XIX, com duas vertentes: a primeira,

dominante, consistiu em aplicar, na medida do possível, ao estudo das sociedades todos os princípios epistemológicos e metodológicos que presidiam ao estudo da natureza desde o século XVI; a segunda consistiu em reivindicar para as ciências sociais um estatuto epistemológico e metodológico próprio, com base na especificidade do ser humano e sua distinção polar em relação à natureza (CHAUÍ, 2003, p. 19)

Esse modelo tem entrado em crise desde o início do século XX, com Einstein e sua teoria da relatividade e as quebras consequentes de concepções de tempo e espaço absolutos de Newton; a mecânica quântica, demonstrando que o observador está sempre implicado no objeto, alterando-o; o questionamento do rigor matemático, assentado no critério de seletividade; os conhecimentos da microfísica, da química e da biologia, considerando, sobretudo em Prigogine, que os sistemas são abertos, auto-organizadores, por isso a imprevisibilidade. Nesse movimento paradigmático, os objetos de investigação no campo educacional estiveram e estão bem ancorados ${ }^{3}$.

Por muito tempo, se acreditou que os objetos educacionais poderiam ser estudados em suas variáveis básicas, cujo estudo analítico, geralmente quantitativo, levaria ao conhecimento "verdadeiro" do fenômeno. Isto se dá através do emprego da quantificação, coleta de dados, do tratamento estatístico e forma de coleta de amostra ampla. A predominância destes estudos esteve (e está) atrelada ao enfoque Positivista em educação. Nesse enfoque, os fatos observados são o centro de interesse dos pesquisadores. Cabe a estes buscar as relações entre os fatos e não suas causas primeiras e finais: "o que interessa ao espírito positivista é estabelecer como se produzem as relações entre os fatos" (TRIVIÑOS, 1995, p. 36).

Se o pesquisar está interessado em estudar sobre o tema mídias na alfabetização de crianças, sua preocupação deve ser enfocada na seguinte questão de pesquisa: Existem relações entre o aprendizado da leitura e da escrita das crianças das escolas públicas municipais de Aracaju e o uso frequente de mídias impressas e visuais, audiovisuais e digitais nas práticas pedagógicas dos docentes? O que vai ser estudado? Exatamente as relações entre as variáveis, isto é, o "aprendizado da leitura e da escrita" e a "frequência (ou não) de uso de diversas mídias em sala de aula”. Variáveis entendidas aqui como elementos constitutivos das hipóteses, consideradas estas como uma "classificação ou medida; uma quantidade que varia um constructo ou conceito operacional que contém ou apresenta valores; aspecto, propriedade ou fator, discernível em um objeto e passível de mensuração" (MARCONI; LAKATOS, 2008, p. 175).

3 Estudos sobre esses paradigmas das ciências na educação encontram-se em Moraes $(1997,2004)$. 
A questão proposta, neste exemplo para ser estudado, deve seguir os mesmos passos de uma pesquisa experimental, apropriando-se do método científico. Método científico é uma exigência de toda e qualquer ciência, sendo este um "conjunto das atividades sistemáticas e racionais que, com maior segurança ou economia, permite alcançar um objetivo - conhecimentos válidos e verdadeiros -, traçando o caminho a ser seguido, detectando erros e auxiliando nas decisões dos cientistas" (MARCONI; LAKATOS, 2008, p. 46) ${ }^{4}$. Isto consiste na observação dos níveis de "leitura dos alunos", evidenciados através de testes e/ou observações e a "frequência (ou não) dos usos de mídias nas práticas pedagógicas dos professores". As correlações estabelecidas entre as variáveis e a comprovação ou não da hipótese enquanto "enunciados gerais de relações entre variáveis e verificação das mesmas significa uma procura das conexões causais que ligam as variáveis" (MARCONI; LAKATOS, 2008, p. 228).

Ao fazer esta investigação, trabalhamos na abordagem quantitativa na qual

os fatos ou os dados são frutos da observação, da experiência e da constatação, e devem ser transformados em quantidades, reproduzidos e reiterados em condições de controle, para serem analisados de modo neutro e objetivo a fim de se formular leis e teorias explicativas dos fatos observados" (CHIZATTI, 2008, p. 29).

Nesse caso, não há diferenciação entre o método aplicado nas ciências humanas ou sociais e nas ciências da natureza. A saber, a determinação do tema: em nosso exemplo, "alfabetização com uso de multimídia”. Em seguida, a definição do problema da pesquisa, já feito, passando para o levantamento da literatura sobre o problema de pesquisa em periódicos, livros, sites, documentos e dados sobre a questão

4 Chamamos a atenção de que não há uma única concepção de ciência, nem também um mesmo método científico que foram historicamente sofrendo alterações, rupturas. A ciência começou a ganhar autonomia em relação a filosofia, proximamente durante o período Renascentista, poderíamos afirmar que a ciência enquanto corpus teórico e metodológico emergiu a partir de então. da alfabetização e os documentos necessários para estabelecer os dados: fichas de alunos e aplicação de questionários. De posse dessas informações, podemos formular as seguintes hipóteses: quanto maior o nível de leitura e de escrita dos alunos, mais alto é o nível sócio-econômico dos alunos; quanto mais fluidez na leitura e escrita dos alunos, maior é o nível de escolaridade dos alunos e o local da moradia. Para levantar os dados dessa pesquisa, construímos instrumentos de pesquisas, no caso, pode ser um questionário aplicado aos pais das crianças nas escolas municipais de Aracaju que ofereçam as primeiras séries. Por fim, realizamos a descrição e o estabelecimento das relações entre os fatos em forma de relatório, explicando o fenômeno. As relações são objetivamente medidas, destacando-se o uso da estatística.

Podemos afirmar que os estudos em educação tiveram, prioritariamente, na utilização do mesmo método de se estudar a natureza, baseadas na concepção do conhecimento científico chamado de positivismo. Suas características são: empirismo, pois o conhecimento positivo, como os sentidos a percebem, diferente das crenças e valores, respeita a separação entre o objeto e o sujeito, que não deve influenciar de modo algum, com procedimentos adequados para eliminar ou reduzir os efeitos dessas intervenções. A experimentação, cuja validade quantitativa, permite que se realizem as experiências nas mesmas condições e generalização dos resultados; leis e previsão, estabelecer leis e prever os comportamentos sociais educacionais (LAVILLE; DIONNE, 1999).

O modelo das ciências naturais e o espírito do positivismo, que se desenvolveu nas ciências humanas desde o século XIX e as primeiras décadas do século XX foram sofrendo criticas e questionados, buscando-se outras alternativas. Um desses questionamentos é a diferença entre um objeto das ciências sociais ou humanas das ciências naturais, pois os fatos humanos ou sociais têm o teor mais complexo. Um bom exemplo disso é tentar explicar a correlação entre variáveis, respondendo à questão do ponto da mensuração: quantas 
mídias são utilizadas ao longo do ano em classe de alfabetização? Há maior frequência de uso de mídias impressas em relação a outras? Qual o desempenho escolar dessas crianças? Sem se perguntar pela dimensão mais subjetiva, como por exemplo: Qual a concepção que a professora e as crianças têm dessas mídias? Quais seus valores educacionais incorporados em sua prática pedagógica em que as mídias se façam presentes? 0 que significa para as crianças e para a professora o contato com o computador e a Internet?

Essa complexidade extensiva aos objetos no campo das ciências humanas ou sociais carece, portanto, de novos enfoques investigativos.

O positivismo mostrou-se, portanto, rapidamente enfraquecido, quando se desejou aplicá-lo no domínio do humano. Considerou-se então outras perspectivas, que respeitassem mais a realidade dos objetos de estudo em ciências humanas; levou-se em conta outros métodos, menos intervenientes e capazes de construir o saber esperado. Para tanto a própria evolução da pesquisa em ciências naturais seria, se não uma inspiração, ao menos um encorajamento. (LEVILLE; DIONNE, 1999, p. 35).

Ainda exemplificando: Será que há relação entre uso das Tecnologias da Informação e Comunicação (TIC) em sala de aula e o desempenho dos alunos em Língua Portuguesa no primeiro ano do Ensino Fundamental da rede pública municipal de São Cristóvão? Ao submetermos os fenômenos à experimentação para demonstrar as relações que os regem, o que fazer? Verificamos quando, quantas vezes e quais momentos as TIC foram usadas nas aulas de ensino da língua portuguesa e quais são as notas, representativas do desempenho dos alunos, em provas (testes) dos alunos nessa disciplina. Também podemos determinar outra turma (controle) na qual as TIC não são usadas em condições similares aquela campo da pesquisa. Em seguida, estabelecemos a relação entre variáveis, que devem ser medidas na hipótese (resposta prévia do problema). A hipótese pode ser: o uso das TIC em aulas de Língua Portuguesa contribui para um maior aprendizado da língua.
Chamamos a atenção de que a internet tem gerado gêneros digitais que podem ser usados nas aulas, especialmente de Língua Portuguesa. Esses gêneros fazem o transito entre a linearidade textual e a hipermídia. Gênero digital como afirma Silva (2008, p. 118), seria todo o “aparato textual em que é possível, eletronicamente, utilizar-se da escrita de forma interativa e dinamizadora": e-mail, chat, blog, vídeo-conferência, fórum etc. Eles têm sido objetos de estudos importantes na compreensão de seus usos potenciadores da prática pedagógica, nos sentidos se de ensinar e de se aprender.

As ciências sociais ou humanas, como ciências específicas, se consolidaram a partir de três enfoques: o estruturalismo, a fenomenologia, e o marxismo. Aqui também afirmamos a abordagem qualitativa em pesquisa, com suas características próprias. Segundo Lüdke e André (1985), a pesquisa é realizada em ambiente natural como fonte direta de dados e o pesquisador como seu principal instrumento; os dados coletados são predominantemente descritivos; a preocupação é com o processo mais que com o produto; ao significado que dão as coisas e a vida são dadas as devidas atenções e as análises dos dados seguem normalmente o processo indutivo. ${ }^{5}$

Como foi dito, compreendemos que os fatos sociais e humanos são complexos para ser estudados de forma objetiva, neutra e buscando comprovar (ou negar) as hipóteses, bem como construindo relações entre variáveis. Sua força é sua fraqueza, o que o caracteriza é um ponto importante de crítica, na medida em que a preocupação em estabelecer relações entre os fatos alheia as consequências dos seus achados. Do positivismo emergiu o positivismo lógico ou neopositivismo, no qual foi incorporado o princípio da verificação (demonstração da verdade), só considerando como cientifico o que for verificável. Arana (2007) destaca a reabertura do debate sobre o positivismo, centrando-se sobre

5 Demo (2001) faz uma análise significativa da abordagem qualitativa, sem desconsiderar a importância da quantitativa. 
sua característica principal - o dado empírico - e do próprio sentido do termo positivo.

Com a fenomenologia, a dimensão subjetiva foi evidenciada, sendo esta o estudo das essências e de todos os problemas. A essência dos objetos de pesquisa, até então subsumida ou negada pelo positivismo emerge e torna-se elemento central na investigação científica. Triviños (1995, p. 47) afirma que na fenomenologia "a interpretação do mundo surge intencionalmente à nossa consciência. Por isso, na pesquisa, eleva o ator, com suas percepções dos fenômenos, sobre o observador positivista". Esse enfoque procura romper com os pressupostos positivistas e ganharam corpus nas ciências humanas ou sociais, nas quais podemos situar os objetos de estudo em educação.

Fini (1997, p. 25) afirma que adotar fenomenologicamente na pesquisa em educação é “descrever o fenômenos e não explicá-los”, nem se preocupar em buscar as relações causais. Apreender no sentido de compreender. Por isso, ao iniciar o trabalho, o pesquisador deverá deixar em suspensão toda crença, teorias e explicações existentes a respeito do que está estudando a respeito do fenômeno que deve ser interrogado. Esse momento é chamado de époche (redução fenomenológica). Os dados são situações vividas pelos sujeitos que são tematizados por eles e, ao descrevê-las, esperamos que os sujeitos o façam de modo preciso. Pressupomos que nesse enfoque há um envolvimento do pesquisador no mundo vivido dos sujeitos da pesquisa. Assim, os achados descrevem a essência do fenômeno, isto é, expressa os conteúdos e significados.

No campo educacional, em nosso exemplo sobre o tema alfabetização com uso de mídias, poderíamos abordar o problema de outro ângulo, no enfoque fenomenológico. Quais são as percepções dos alunos da rede pública municipal de Aracaju que estão em fase de aprendizado da leitura e da escrita sobre o seu próprio aprendizado, bem como dos professores e dos pais dos alunos? Aqui se põe em evidência as percepções dos sujeitos, pais, professores e alunos, bem como os significados que cada um destes sujeitos tem sobre o aprendizado da leitura e da escrita com multimídias. É preciso nos perguntarmos pelos sujeitos que se situam ou que vivenciam os processos educativos (o mundo vivido da escola).

Freitas (2001, p. 83) fez um estudo sobre avaliação da aprendizagem na formação online, a partir de estudos hermenêuticos. Esses estudos fazem parte de uma tendência da fenomenologia. A autora buscou compreender, interpretar e recontextualizar a dinâmica do processo vivido por seus interlocutores - professores e alunos. Em seu estudo, reconhece as pontecialidades dos ambientes virtuais de aprendizagem (AVA) e da avaliação como "atividade interativa, complexa e produtora de significados”. O ciberespaço, como mundo vivido no AVA, tem ganhado interesses crescentes pelos investigadores em educação.

Ao tratar o objeto de pesquisa nesse enfoque, busca-se, segundo Mansine (1981), o desvelar do fenômeno para além de sua aparência, da compreensão do vivido e se desenvolve em três etapas 1 . Discussão e ação, cabendo aos pais e professores trazerem suas percepções sobre o processo de aprendizagem dos alunos da leitura e da escrita; 2. Reflexão, buscar significados sobre o dito pelos sujeitos, sem utilizar nenhuma categorização como referência na tentativa de compreender o processo de aprendizagem como é, como é percebido, em seguida. 3. Interpretação e busca vivência (essência dos sujeitos).

Na educação, outra corrente também bastante difundida foi o funcionalismo (ideia de função). 0 método funcionalista é a interpretação do que foi pesquisado. Leva-se em conta que a sociedade é formada por partes componentes diferenciadas, inter-relacionadas e interdependentes, satisfazendo cada uma das funções essenciais da vida social. 0 referido método estuda a função de suas unidades como um sistema organizado de atividades. Podemos analisar principais funções presentes nas escolas, que deem conta 
do trabalho pedagógico para que o mesmo se realize satisfatoriamente. Averiguamos também a função das ações e rotinas escolares para garantir o sucesso escolar. A escola é vista como um todo em funcionamento, um sistema de ações e o papel de cada um dos elementos da escola é compreendido como funções no complexo de estrutura e organização.

O estruturalismo é outro enfoque da pesquisa social e humana que permitiu criar métodos específicos para os objetos, afirmando que os fatos humanos assumem a forma de estruturas, "isto é, de sistemas que criam seus próprios elementos dando a eles sentido pela posição e pela função que ocupam no todo" (CAHUI, 2000, p. 229). Uma estrutura é um princípio ordenador, diferenciador e transformador; por isso, uma totalidade dotada de sentido. Tomamos como parte de investigação de um modelo que represente 0 objeto de estudo retornando ao concreto, desta vista como uma realidade estruturada e relacionada com a experiência do sujeito social. Ele caminha do concreto para o abstrato, do abstrato para o concreto. Como exemplo, podemos estudar as relações pedagógicas e a posição que estas relações determinam os indivíduos da escola, com a finalidade de criar um modelo de gestão que retrate a estrutura escolar em que ocorrem tais relações. Para penetrar na realidade concreta, a mente cria modelos, que não são diretamente observáveis na própria realidade, mas a retratam, para explicar a totalidade da realidade do fenômeno, buscando as relações em si, não os fatos isolados.

Em educação, muitos estudos dentro de uma perspectiva pós-estruturalista têm se desenvolvido como, a exemplo, os sustentados pelas ideias de Michel Foucault. Apesar da dificuldade de enquadramento teórico, suas elaborações têm contribuído para problematizações da pesquisa em educação sobre temas diversos que tratam da disciplina/indisciplina escolar, punições, coerções pedagógicas, relações entre poder e saber, jogos de verdade, discursos e seus enunciados. Algumas dessas pesquisas podem ser lidas no livro organizado por Peters e Besley (2008).
0 enfoque marxista permitiu-nos compreender "que os fatos humanos são instituições sociais e históricas produzidas não pelo espírito e pela vontade dos indivíduos, mas pelas condições objetivas nas quais a ação e o pensamento humanos devem realizar-se" (CHAUÍ, 231, p. 231). Esse enfoque considera que as primeiras instituições são econômicas, como base das análises marxistas, permitindo entender as mudanças históricas que não resultam das ações súbitas de grupos ou pessoas, mas de lentos processos sociais, econômicos e políticos. Trouxe-nos grande contribuição de que os fenômenos sociais que passaram, nesta abordagem, a ser expressões e resultados de contradições sociais, de lutas e conflitos sociopolíticos determinados pelas relações econômicas.

O marxismo compreende três aspectos fundamentais: o materialismo histórico, o materialismo dialético e a economia política. Considera a matéria como princípio primordial e o espírito como secundário. A consciência é produto da matéria e o mundo existe independente da consciência. 0 materialismo dialético é a base filosófica na tentativa de encontrar explicações coerentes, lógicas e racionais para os fenômenos da natureza, da sociedade e do pensamento, cujo critério mais importante é a prática social como critério de verdade. 0 materialismo histórico é a ciência do marxismo que resulta à força de ideias capazes de provocar mudanças nas bases econômicas que as originou. Esclarecem conceitos como ser social, meios de produção, forças produtivas, modos de produção. As categorias do materialismo dialético são: a matéria, objetos e sistemas que existem no mundo social. Ela é incriável, indestrutível e capaz de se autodesenvolver. A consciência é o reflexo da matéria (TRIVIÑOS, 1987).

Em um enfoque marxista, podemos considerar o seguinte problema de pesquisa: Quais os aspectos no desenvolvimento do aprendizado da leitura e da escrita em nível local regional e nacional e suas relações com o processo educacional da comunidade e como se apresentam as contradições desse apren- 
dizado em relação ao projeto pedagógico, à metodologia de sala de aula do professor, aos usos das mídias e ao local onde a escola se situa, dos alunos do primeiro ano do Ensino Fundamental da rede municipal de Aracaju-Se? Aqui se dá ênfase à historicidade do objeto, suas relações em nível macro e micro, estabelecendo possíveis contradições. Estudos em uma perspectiva crítica permitem leitura crítica das mídias, compreendendo-as no lugar central em que ocupam na sociedade atual (GUARESCHI; BIZ, 2005). Poderemos ainda analisar a distribuição de computadores na escola, a partir de um olhar otimista a respeito das potencialidades dessa mídia, mas vinculando nossa análise ao entendimento dos interesses econômicos e políticos envolvidos em alimentar a produção desses suportes tecnológicos pela indústria.

Cada um destes enfoques enuncia seus métodos de pesquisa, o que implica em etapas definidas para se fazer a investigação. A elaboração de um problema já anuncia o quadro referencial que se deseja trabalhar. No sentido geral, podemos considerar que os objetos de investigação no campo educacional se apropriam de diferentes quadros de referências, com seus respectivos métodos e instrumentos de pesquisa para se fazer. Esses enfoques não foram esgotados aqui, pois, deles outros emergiram.

Os enfoques tratados de forma nuclear se dividem e dão origem a outros, a exemplo do neopositismo, do estruturalismo-funcionalista, do fenômeno situado, do pós-marxismo etc. São incursões que exigem determinados mapeamentos sobre o que permanece e o que se rejeita ou acrescenta a cada um dos enfoques.

Os fundamentos teóricos e metodológicos da pesquisa implicam necessariamente no problema a ser investigado, no método que orienta o desenvolvimento das etapas da pesquisa, no tipo de pesquisa que se deseja realizar. Autores como Kincheloe (2007, p. 15) atualiza esta questão propondo a bricolagem como a ampliação de métodos de pesquisa. Essa palavra de origem francesa bricoleur, "processo de emprego dessas estratégias metodológicas à medida que são necessárias no desenrolar do contexto da situação de ensino", trata-se de uma noção interdisciplinar, na qual os pesquisadores são negociadores metodológicos, subvertendo os limites da ciência disciplinar. Um exemplo disso são os estudos culturais, que procuram lidar com um diálogo inter-disciplinar e extra-disciplinar para dar conta dos objetos.

\section{ABORDAGENS E TIPOS DE PESQUISAS}

As duas grandes abordagens, que historicamente mantiveram-se em separado, são a quantitativa e a qualitativa para se estudar os fenômenos humanos ou sociais. A primeira, focada no positivismo, limitou-se à relação entre variáveis. A segunda, cuja origem remonta ao estruturalismo e o funcionalismo, próximas ao positivismo, buscaram outros elementos significativos, em particular no campo da educação para se investigar.

É importante salientar que o tipo de pergunta e de problema que fazemos em relação à pesquisa quali- tativa se diferencia da quantitativa, de acordo com a fundamentação teórica que se adota. Os fenômenos que são estudados na pesquisa educacional são essencialmente fenômenos sociais, que são constituídos de atos situados no tempo, atividades que são ações realizadas em alguma situação, significados envolvendo produções verbais das pessoas envolvidas na situação, envolvimento do sujeito a uma situação de estudo, intercâmbio entre eles e o foco ou unidade que se deseja estudar. 
Os estudos etnográficos migrados da antropologia e da sociologia fomentaram também o campo educacional. Etnografia é a descrição de "um sistema de significados culturais de um determinado grupo" (LUCKE, ANDRÉ, 1985). No caso da educação, seria o de pensarmos o ensino e a aprendizagem no contexto cultural mais amplo, na ida ao campo, redescobrimos o problema, mergulhamos na situação e o redefinimos. Devemos realizar a maior parte do seu trabalho no campo pessoalmente e precisamos ter uma longa vivência para entender as regras, os costumes e as convenções que regem o grupo que estamos estudando. Caso seja possível, devemos ter experiências com outras realidades, outras culturas, pois nos ajuda a entender melhor o sentido do que estamos investigando. Utilizamos de vários métodos de coletas de dado, principalmente através da observação direta do grupo estudado, de entrevistas, de levantamento de histórias de vida, análise documental testes, filmes, fotografias, dentre outras formas que possam fornecer um quadro mais vivo e completo da situação estudada.

Nesse sentido, os estudos etnográficos apresentam uma grande quantidade de dados primários. Seu método passa, necessariamente, pelas etapas de exploração, decisão e descoberta. A seleção e definição de problema, escolha do local e os contatos para entrar no campo (sem linha teórica predeterminada, nem hipóteses formuladas a priori) vão se construindo durante o processo. Se formos estudar a troca de mensagens, através do fórum de discussão, entre professores e alunos de um curso realizado a distância, nosso interesse geral é o de tentarmos entender como se processa essas comunicações, em que medida esse debates ocorrem argumentações sobre o conteúdo tratado e o que tipo de enunciado os professores elaboram para discuti-lo. Não temos que ter claro o percurso que vamos fazer nem que tipo de hipótese podemos construir. Apenas sabemos a necessidade de acesso ao campo - no caso o Ambiente Virtual de Aprendizagem (AVA), ao grupo de alunos e professores envolvidos no curso e a questão proposta no Fórum de discussão.
Um dos primeiros passos é o de buscarmos informações sistematizadas sobre o campo, no caso o AVA, bem como sobre os membros que participam ou deveriam participar da discussão. É importante que busquemos informações sobre processos de aprendizagem e de ensino em cursos ministrados a distância além de estudarmos também aspectos do próprio AVA onde o curso está sendo ministrado e, sobretudo, sobre as novas formas de linguagem em espaços virtuais.

Nesse contexto, vamos acumulando informações e na observação direta do campo, no caso, o Fórum de discussão, procuramos encontrar explicações subjacentes ao fenômeno estudado, acumulando informações sobre o conteúdo discutido, os níveis de interação e de interatividade estabelecidas no AVA, as formas de linguagens nos processos comunicacionais entre os envolvidos. Além disso, sobre o próprio desenho do AVA, a distribuição de ferramentas, dentre elas o Fórum de discussão.

Outro bom exemplo de pesquisa do tipo etnográfico são aquelas que estudam o cotidiano escolar, voltando-se para as vivências e experiências dos indivíduos e grupos que participam e constroem o cotidiano escolar. 0 que caracteriza mais a pesquisa etnográfica é um contato direto e prolongado do pesquisador com a situação e as pessoas ou grupos selecionados. Ele obtém uma grande quantidade de dados descritivos, locais de pessoas, de ações, interações, fatos, linguagem, expressões, fotografia em função do que são feitas analises e interpretações, sempre se movendo em campo aberto, entre a observação e análise, entre a teoria e empiria. Sua técnica principal é a observação participante, na qual o pesquisador passa a fazer parte integrante do grupo que estuda e contribui para que certas situações ocorram (VIANNA, 2003). O estudo do cotidiano escolar se coloca como funda-
mental para se compreender como a escola desem-
penha o seu papel socializador, seja na transmissão
dos conteúdos acadêmicos, sejam na veiculação das
crenças e valores que aparecem nas ações, interações,
nas rotinas e nas relações sociais que caracterizam o
cotidiano da experiência escolar (ANDRE, 1989, p. 38) 
A pesquisa do cotidiano escolar envolve três dimensões inter-relacionadas: a institucional, a interação em sala de aula e a história de cada sujeito no cotidiano escolar. Estudar a escola significa estudar a escola em sua singularidade, como parte de uma totalidade social e com a qual mantêm determinadas formas de relacionamento. A atividade de analise se faz paralela à observação.

Chizzotti (1999) chama-nos atenção que as pesquisas sobre o cotidiano ganharam força nos anos 50 , marcadas pelos estudos experimentais que procuram analisar as estratégias de experimentação clássica: 0 repetitivo, o idêntico, as descrições das ações tornam-se analisados, principalmente pela psicologia, procurando quantificar e analisar as condutas, as normas, os atos os comportamentos, decorrente das interações sociais. Posteriormente, essa forma de pesquisa passou a ser questionada e muitos estudos do cotidiano passaram a ser tributários da fenomenologia, especialmente do interacionismo simbólico, colocando em destaque as interações humanas. Além desse enfoque, outros tantos foram realizados na perspectiva dialética, com a valorização do fato observado e a atividade criadora do sujeito que observa, revelando, sempre as contradições entre o todo e a parte e os vínculos de saber e agir dos homens (CHIZZOTTI, 2008).

A pesquisa ação tem como objetivo transformar a realidade e produzir conhecimentos relativos a essa transformação. É segundo Thiollent (1988) uma estratégia metodológica normalmente realizada em organizações, escolas, associações etc. Há duas percepções da pesquisa ação segundo Barbier (2007). A pesquisa experimental para ação, na qual o pesquisador explora aspectos da realidade que deseja intervir, elabora o enunciado do problema de pesquisa, faz o planejamento do seu projeto de intervenção, realiza e apresenta análise dos resultados, bem como a tomada de decisão. A nova pesquisa-ação, como uma ciência da práxis, exercida por quem está envolvido no local onde atual, centrada em uma abordagem multirrefencial.
$\mathrm{Na}$ educação, os próprios docentes assumem o papel de professores-pesquisadores, responsabilizando-se pelas próprias ações transformadoras em seu campo de atuação. Dessa forma, os professores percebem "o processo educativo como passível de pesquisa" e "compreendem a pesquisa como atividade social e política, portanto ideológica" (IDEM, p. 60). Há uma implicação do sujeito com o objeto. 0 pesquisador-professor ${ }^{6}$ deseja observar a reação dos alunos diante de determinadas práticas pedagógicas realizadas no laboratório de informática. Para tanto, ele pode usar diários, registros audiovisuais, análise dos conteúdos etc. para, em seguida, propor um projeto pedagógico em que os alunos possam criar formas de interação intensas em ambientes virtuais de aprendizagem: planejar, agir, observar e refletir, depois replanejar. Tornam-se elementos significativos para operar determinadas mudanças em sua própria prática educativa, tendo como propósito uma radical mudança no fazer pedagógico no Laboratório de Informática.

0 estudo de caso visa à descoberta, enfatiza a interpretação em contexto, retrata a realidade de forma complexa e em várias dimensões. Para o realizarmos, precisamos usar uma variedade de fontes de informações e apresentarmos diferentes e conflitantes pontos de vista de uma situação social objeto de estudo. Trata-se, sumariamente, da compreensão de uma instância particular: uma instituição, uma escola, um indivíduo. Segundo Lücke e André (1985, p. 17), “o interesse, portanto, incide naquilo que ele tem de único, de particular, mesmo que posteriormente venham a ficar evidentes certas semelhanças com outros casos ou situações". Eles podem ser qualitativos ou quantitativos.

O desenvolvimento do estudo de caso ocorre em três fases: exploratória, delimitação do estudo e análise sistemática e a elaboração do relatório (LÜCKE; ANDRÉ, 1985, p.17). Podemos, por exemplo, estudar sobre o tema potencialidade do blog como ferramen-

6 Estudos sobre o professor pesquisador podem ser vistos em BortoniRicardo (2008). 
ta pedagógica na interação entre alunos e professores. Examinamos a literatura que discute sobre blog, ambientes virtuais de aprendizagem, objetos virtuais de aprendizagem que ajudam a compreender de uma forma mais próxima o que desejamos estudar. Também observarmos blogs voltados para educação, levando em conta nossa própria experiência com a ferramenta etc. 0 importante é definirmos claramente a problemática da pesquisa. Também um momento de explorar fontes, entrarmos em contato com o campo e localizarmos possíveis informantes para a pesquisa. Podemos, então, considerar que o nosso estudo é o de analisar o blog “Educação e ciberespaço”, como espaço interativo e de interação entre os alunos participantes da disciplina Tecnologias da Informação e Comunicação do curso de Pedagogia da Universidade Federal de Sergipe. Em seguida, passamos para a análise sistemática dos dados e a redação do relatório.
Segundo Triviños, os estudos de caso podem ser histórico-organizacionais, focados na vida de uma escola, de uma universidade, casos observacionais, centrados em sala de aula, reuniões pedagógicas, e história de vida, realizados normalmente com entrevistas semiestruturadas sobre a vida (ou aspectos dela) de professores que tiveram e têm significado em determinada rede social. A história de vida pode ser de natureza biográfica ou ter forma autobiográfica, na qual se relatam suas expressões, sentimentos, percepções vivenciadas no contexto de sua trajetória de vida. Além disso, há os estudos comparativos de caso em que, segundo o autor, se realiza a justaposição dos fenômenos. A análise de conteúdos também pode ser usada na educação como método de tratamento e análise de informações, permitindo passar de elementos descritivos à interpretação dos autores sociais.

\section{EM BUSCA DE CAMINHOS METODOLÓGICOS}

A pesquisa em educação tem se constituído no âmbito das ciências sociais ou humanas e assumindo os mesmos solavancos de suas mutações teóricas e metodológicas. Essa compreensão nos permite entender que os objetos em pesquisa educacional têm sido construídos e investigados dentro destes parâmetros. Remetemos a discussão aos caminhos que se desenham na atualidade: bricolagens, ecletismos metodológicos, ou outras possibilidades investigativas.

Em um ou outro sentido, salvando-se as críticas, as mídias na educação têm ganhado interesse e força. Elas são apenas recursos didáticos e, como tais, têm os limites de trabalhar o pedagógico de uma forma mais motivadora? As TIC são apenas meios comunicacionais capazes de gerar formas de interações professor aluno diferenciadas de outras práticas presenciais e sustentadas na oralidade e no texto impresso? Ou elas são ferramentas pedagógicas estruturadora dos novos modos de ensinar e de aprender?

Essas questões ficam em aberto, traduzindo possibilidades investigativas que podem ser exploradas em diferentes enfoques e abordagens de pesquisa. Basta, para tanto, nos perguntarmos qual é a nossa problemática de pesquisa e sobre o desenho metodológico que precisamos fazer para encontrar respostas e produzir o conhecimento científico em mídias e educação. 


\section{REFERÊNCIAS}

ARANA, Hermes G. Positivismo: reabrindo o debate. São Paulo: Autores Associados, 2007.

BARBIER, René. A Pesquisa-Ação. Brasília. Tradução de Lucie Didio. Ed. Liber Livro. 2007.

BORTONI-RICARDO, Stella Maris. 0 professor pesquisador: introdução à pesquisa qualitativa. São Paulo: Parábola Editorial, 2008.

CHAUI, Marilena. Convite a filosofia. São Paulo: Ática, 2006.

CHIZZOTTI, Antonio. $\mathbf{0}$ cotidiano e as pesquisas em educação. FAZENDA, Ivani (org.). Novos enfoques da pesquisa educacional. 3. ed. São Paulo: Cortez, 1999. p. 85-98.

CHIZZOTTI, Antonio. Pesquisa em ciências humanas e sociais. 9. ed. São Paulo: Cortez, 2008.

DEMO, Pedro. Pesquisa e informação qualitativa. 4. ed. São Paulo: Papirus, 2001.

FINI, Maria Inês. Sobre a pesquisa qualitativa em educação, que tem a fenomenologia como suporte. BICUDO, Maria Aparecida Viggiani; ESPÓSITO, Vitória Helena Cunha (orgs.) Pesquisa qualitativa em educação. 2. ed. Piracicaba, São Paulo: Editora Unimed, 1997. p. 23-33.

FREITAS, Maria Auxiliadora Silva. Os estudos hermenêuticos e sua contribuição na avaliação da aprendizagem online. MERCADO, Luís Paulo Leopoldo (org.). Fundamentos e práticas na educação a distância. Editora EDUFAL, 2009

GRUZINSKI, Serge. 0 que é um objeto mestiço? PASAVENTO, Sandra Jatahy (Org.). Escrita, linguagem, objetos: leituras de História cultural. Bauru, São Paulo: EDUSC, 2004. p. 253-278.
GUARESCHI, Pedrinho A.; BIZ, Osvaldo. Mídia, educação e cidadania: tudo que você deve saber sobre mídia. Petropólis, RJ: Vozes, 2005.

KINCHELOE, Joe L.; BERRY, Kathleen S. Pesquisa em educação: conceituando a bricolagem. Tradução Roberto Cataldo Costa. Porto Alegre: Artmed, 2007.

KÖCHE, José Carlos. Fundamentos de metodologia científica: teoria da ciência e prática da pesquisa. 17 ed. Petropólis, Rio de Janeiro: Vozes, 1997.

KUHN, Thomas s. A estrutura das revoluções científicas. Tradução: de Beatriz Vianna Boeira e Nelson Boeira. 5. ed. São Paulo: Perspectiva, 1997.

LAVILLE, Christian; DIONNE, Jean. A construção do saber: manual de metodologia da pesquisa em ciências humanas. Tradução: Heloísa Monteiro e Francisco Setteneri. Porto Alegre: Editora Artes Médicas; Belo Horizonte: Editora UFMG, 1999.

LÜCKE, Menga; ANDRÉ, Marli E.D.A. Pesquisa em educação - temas básicos de educação e ensino. São Paulo. Ed.Pedagógica e Universitária Ltda-EPU. 1986.

MERCADO, Luís Paulo Leopoldo (org.). Pensamento eco-sistêmico: educação, aprendizagem e cidadania no século XXI. Petropólis, RJ: Vozes, 2004.

MERCADO, Luís Paulo Leopoldo (org.). Vivências com aprendizagem na Internet. Alagoas: EDUFAL, 2005

MERCADO, Luís Paulo Leopoldo (org.). Práticas de formação de professor a distância. Maceió: Editora EDUFAL, 2008.

MERCADO, Luís Paulo Leopoldo (org.). Fundamentos e práticas na educação a distância. Editora EDUFAL, 2009. 
MORAES, Maria Cândida. Paradigma educacional emergente. São Paulo: Papirus, 1997.

MARCONI, Marina de Andrade; LAKATOS, Eva Maria. Metodologia científica: ciência e conhecimento científico, métodos científicos, teoria, hipóteses e variáveis, metodologia jurídica. 5 ed. São Paulo: Atlas, 2008.

MARCONI, Marina de Andrade; LAKATOS, Eva Maria. Técnicas de pesquisa: planejamento e execução de pesquisas, amostragens e técnicas de pesquisa, elaboração, análise e interpretação de dados. 7 ed. São Paulo: Atlas, 2008.

MASINI, Elcie. Enfoque fenomenológico de pesquisa em educação. FAZENDA, Ivani (org.). Metodologia da pesquisa educacional. São Paulo: Cortez, 1989. p. 5967.

PETERS, Michael; BESLEY, Tina e colaboradores. Por que Foucault? Novas diretrizes para a pesquisa educacional. Tradução Vinícius Figueira Duarte. Porto Alegre: Artmed, 2008.

POLÓNIO, Diogo Maria dos Matos. Epistemologia das ciências da educação: a emergência de uma Ciência da Educação e o papel fundamental da Filosofia da Educação. http://www.ipv.pt/millenium/pce6_dmp. htm. Acesso em: 12 jul. 2012.

\section{QUEIROZ, Tânia Dias. Dicionário prático de pedago-} gia. São Paulo: Rideel, 2003.

SANTOS, Boaventura de Sousa. Um discurso sobre as ciências. 14. ed. Porto: Edições Apontamento, 2003.

SEVERINO, Antônio Joaquim. Problemas e dificuldades na condução da pesquisa no curso de pós-graduação. FAZENDA, Ivani (org.). Novos enfoques da pesquisa educacional. São Paulo: Cortez, 2004. p. 27-35.

SILVA, Edilayne Dantas da. Gêneros digitais como material didático nas aulas de Língua Portuguesa. MERCADO, Luís Paulo Leopoldo (org.). Práticas de formação de professor a distância. Maceió: Editora EDUFAL, 2008. p. 117-134.

TRIVIÑOS, A.N.S. Introdução à pesquisa em ciências sociais: a pesquisa qualitativa em educação. São Paulo: Atlas: 1987.

VIANNA, Heraldo Marelim. Pesquisa em educação: observação. Brasília: Plano Editora, 2003.
1 Possui graduação em Pedagogia pela Universidade Federal de Sergipe (1985), Mestrado em Educação pela Universidade Federal de Sergipe (1996), Doutorado Sanduíche pela Universidade Aberta de Lisboa (2006) e Doutorado em Educação, pela Universidade Federal do Rio Grande do Norte (2007). É professora do Departamento de Educação e do Mestrado em Ensino de Ciências e Matemática na Universidade Federal de Sergipe. E-mail: sssobral@gmail.com 